\title{
Study on the Fruit Quality of Different Canopy and Tree Shapes of Huangguogan Citrus
}

\author{
Liping Tan ${ }^{1}$, Zhaofang Chen ${ }^{1}$, Youting Yang ${ }^{1}$, Qing Zhang ${ }^{1}$, Xia Qiu ${ }^{1}$, Tie Wang ${ }^{1}$, Honghong Deng ${ }^{1}$, Ling Liao ${ }^{1}$, Guochao \\ Sun $^{2}$, and Zhihui Wang ${ }^{2, *}$ \\ ${ }^{1}$ College of Horticulture, Sichuan Agricultural University, 611130 Chengdu, Sichuan, China \\ ${ }^{2}$ Institute of Pomology \& Olericulture, Sichuan Agricultural University, 611130 Chengdu, Sichuan, China
}

\begin{abstract}
In this paper, Shimian yellow citrus fruit was used as material to study the differences of HuangGuo citrus fruit strains by sampling, measuring and analyzing the fruit quality according to different shapes and canopy. The results showed that: in the yellow fruit citrus plants fruit quality was better than the performance of the lower part of the upper canopy, appearance quality did not change significantly, little difference; intrinsic quality significantly different soluble solids and sugar content than other obvious difference; round tree fruit quality was better than natural growth happy shape and form.
\end{abstract}

\section{Introduction}

Huangguogan, belonging to the genus Rutaceae Citrus, is a new hybrid orange variety selected by Sichuan Agricultural University [1]. Originally produced in Xinmian Town, Shimian County, Sichuan Province, it is especially suitable for planting in dry and hot valleys at an altitude of 700 1200 m. Huangguogan has excellent fruit quality, high yield and high yield, late maturity and storability, strong stress resistance, crispy and juicy meat, sweet and sour and delicious, relatively slag, and is deeply loved by the masses in Sichuan and Yunnan [2]. However, in recent years, the research of Huangguogan has found that the fruit shape was very different, the fruit quality was uneven, and the fruit quality difference between and within the plant was obvious.

It was of great significance to explore the fruit quality differences of different canopies and different tree shapes in Huangguogan, and it was of great significance to in-depth study to find out the reasons for its formation, and to further improve the quality of Huangguogan fruit and increase the consistency of its fruit quality. The investigation on the different performance of different canopy fruit quality in Shimian Huangguogan plant and the relationship between different tree shapes and fruit quality are carried out to provide a theoretical basis for further research and promote the development of Shimian Huangguogan industry.

\section{Materials and Methods}

\subsection{Experimental materials}

In Shimian County, 9 trees with a row spacing of $3 \times 4 \mathrm{~m}$ and an 8-year-old tree were basically uniform and robust. They were 3 round-headed trees, 3 open-hearted trees, and 3 natural-growing trees.

\subsection{Sample Collection}

The method of Wei Qinping, Wertheim, and Wagenmarkers [3] divided it into three canopies: upper, middle and lower canopy ; the fruits were picked in 4 directions of east, south, west, and north on each layer, and 3 fruits were picked at each point, and they were mixed as a layer for sampling; the fruit quality of 12 points was mixed into one fruit quality of the tree.

\subsection{Sample determination}

Single fruit was measured by electronic balance, measured three times in total, and then averaged; horizontal and vertical diameters were measured with vernier calipers, soluble solids were measured with WYT-4 handheld refractometer [4]; vitamin C content was measured with 2,6-dichloro Phenol indophenol titration method; titratable acid content is measured by $\mathrm{NaOH}$ neutralization titration; reducing sugar and invert sugar content are measured by Fehling solution redox titration [5], and the total sugar content is calculated.

\subsection{Statistical Analysis}

The test data used Office Excel (2003) software and (2013) for statistical analysis, analysis of variance and significance analysis.

\footnotetext{
*Corresponding author: Zhihui Wang@wangzhihui318@126.com
} 


\section{Results and analysis}

\subsection{Different canopies of Huangguogan fruit quality}

The results of fruit appearance quality measurement (Table 1) showed that the average fruit weight of different canopy fruits was between 132.07-130.15 g. The fruit weight of the upper layer was the largest, and the fruit weight of the lower layer was the smallest. The vertical and horizontal diameters of different canopy fruits were the largest in the upper layer, $6.60 \mathrm{~cm}$ and
$6.47 \mathrm{~cm}$, respectively; the lower fruit shape index was the largest. However, there was no significant difference in the appearance quality of the fruits in the upper, middle and lower canopies.

The results of the intrinsic quality of the fruit (Table 2) showed that that the internal quality of the fruit, soluble solids, vitamin $\mathrm{C}$, titratable acid, and sugar content were the highest in the upper canopy, the middle layer, and the lowest in the lower layer. The sugar-acid ratio of the fruit was the highest in the upper canopy, the lower and the middle layer, the lowest, but the difference was small.

Table 1. Differences in appearance quality of Huangguogan fruits with different canopies.

\begin{tabular}{|c|c|c|c|c|}
\hline Different canopy & $\begin{array}{c}\text { Single fruit } \\
\text { weight/g }\end{array}$ & $\begin{array}{c}\text { Longitudinal } \\
\text { diameter/cm }\end{array}$ & Horizontal diameter/cm & Fruit shape index \\
\hline Upper part & $132.07 \mathrm{a}$ & $6.60 \mathrm{a}$ & $6.47 \mathrm{a}$ & 1.02 \\
\hline Central & $131.98 \mathrm{a}$ & $6.58 \mathrm{a}$ & $6.46 \mathrm{a}$ & 1.02 \\
\hline Lower part & $130.15 \mathrm{a}$ & $6.56 \mathrm{a}$ & $6.40 \mathrm{a}$ & 1.03 \\
\hline
\end{tabular}

Note: The LSD method was used to test the significance of differences. The same letters indicated that the difference was not significant, lowercase letters indicate 5\% significance level, and uppercase letters indicate $1 \%$ significance level. The same below.

Table 2. Differences in internal quality of Huangguogan fruits with different canopies.

\begin{tabular}{|c|c|c|c|c|c|c|c|}
\hline $\begin{array}{c}\text { Different } \\
\text { canopy }\end{array}$ & $\begin{array}{c}\mathrm{TSS} \\
/ \%\end{array}$ & $\begin{array}{c}\mathrm{Vc} \\
/ \mathrm{mg} \cdot 100 \\
\mathrm{~mL}\end{array}$ & $\begin{array}{c}\mathrm{acid} \\
/ \mathrm{mg} \cdot 100 \mathrm{~mL}^{-1}\end{array}$ & $\begin{array}{c}\text { Reducing } \\
\text { sugar } \\
/ \mathrm{mg} \cdot 100 \mathrm{~mL}^{-1}\end{array}$ & $\begin{array}{c}\text { Invert sugar } \\
/ \mathrm{mg} \cdot 100 \mathrm{~mL}^{-1}\end{array}$ & $\begin{array}{c}\text { Total sugar } \\
/ \mathrm{mg} \cdot 100 \mathrm{~mL}^{-1}\end{array}$ & $\begin{array}{c}\text { Sugar-acid } \\
\text { ratio }\end{array}$ \\
\hline Upper part & $11.24 \mathrm{aA}$ & $30.78 \mathrm{aA}$ & $0.86 \mathrm{aA}$ & $4.75 \mathrm{aA}$ & $9.59 \mathrm{aA}$ & $9.34 \mathrm{aA}$ & 10.96 \\
\hline Central & $10.98 \mathrm{abAB}$ & $29.84 \mathrm{aAB}$ & $0.85 \mathrm{aA}$ & $4.51 \mathrm{aA}$ & $9.20 \mathrm{abAB}$ & $8.97 \mathrm{abAB}$ & 10.43 \\
\hline Lower part & $10.62 \mathrm{bB}$ & $28.28 \mathrm{bB}$ & $0.82 \mathrm{aA}$ & $4.17 \mathrm{bB}$ & $9.03 \mathrm{bB}$ & $8.79 \mathrm{bB}$ & 10.71 \\
\hline
\end{tabular}

\subsection{Different tree shape Huangguogan fruit quality difference performance}

The results of the appearance quality of different treeshaped fruits (Table 3 ) showed the appearance quality of the round-headed fruit was slightly better than that of the other two tree shapes, but there was no significant difference in the fruit appearance quality of the three tree shapes.

The results of the internal quality of different treeshaped fruits (Table 4) showed that the soluble solids, vitamin $\mathrm{C}$, and titratable acid content of different treeshaped fruits had no significant differences, but there were significant differences in the sugar content of different tree-shaped fruits. Naturally grown fruits had the lowest reducing sugar at $4.32 \mathrm{mg} \cdot 100 \mathrm{~mL}^{-1}$, which was significantly lower than round-headed and openhearted fruits; the highest inverted sugar content of round-headed fruits was $9.52 \mathrm{mg} \cdot 100 \mathrm{~mL}^{-1}$, and the lowest content of natural growth was $8.94 \mathrm{mg} \cdot 100 \mathrm{~mL}^{-1}$; There were significant differences in sugar content between different tree shapes, and the total sugar content of the natural growth shape $\left(8.71 \mathrm{mg} \cdot 100 \mathrm{~mL}^{-1}\right)$ was extremely significantly lower than the round head shape and the open shape.

Table 3. Different tree shapes of Huangguogan fruit appearance quality difference performance.

\begin{tabular}{|c|c|c|c|c|}
\hline Tree shape & Single fruit weight/g & Longitudinal diameter/cm & Horizontal diameter/cm & Fruit shape index \\
\hline Open heart shape & $129.66 \mathrm{a}$ & $6.49 \mathrm{a}$ & $6.47 \mathrm{a}$ & 1.00 \\
\hline Round head shape & $140.20 \mathrm{a}$ & $6.76 \mathrm{a}$ & $6.60 \mathrm{a}$ & 1.03 \\
\hline Natural growth shape & $122.17 \mathrm{a}$ & $6.49 \mathrm{a}$ & $6.49 \mathrm{a}$ & 1.00 \\
\hline
\end{tabular}


Table 4. Effects of phosphorus and potassium bacterial fertilizer on soil nutrients during fruit ripening.

\begin{tabular}{|c|c|c|c|c|c|c|c|}
\hline Tree shape & $\begin{array}{l}\text { TSS } \\
/ \%\end{array}$ & $\begin{array}{c}\mathrm{Vc} \\
/ \mathrm{mg} \cdot 100 \\
\mathrm{~mL}^{-1}\end{array}$ & $\begin{array}{c}\text { acid } \\
\underset{\mathrm{mL}^{-1}}{ } \cdot 100\end{array}$ & $\begin{array}{c}\text { Reducing } \\
\text { sugar } \\
/ \mathrm{mg} \cdot 100 \mathrm{~mL}^{-} \\
1\end{array}$ & $\begin{array}{l}\text { Invert sugar } \\
/ \mathrm{mg} \cdot 100 \\
\mathrm{~mL}^{-1}\end{array}$ & $\begin{array}{l}\text { Total sugar } \\
/ \mathrm{mg} \cdot 100 \\
\mathrm{~mL}^{-1}\end{array}$ & $\begin{array}{l}\text { Sugar- } \\
\text { acid } \\
\text { ratio }\end{array}$ \\
\hline Open heart shape & $10.85 \mathrm{aA}$ & $30.08 \mathrm{aA}$ & $0.82 \mathrm{aA}$ & $4.52 \mathrm{aA}$ & $9.36 \mathrm{bB}$ & $9.12 \mathrm{bA}$ & 11.12 \\
\hline Round head shape & $11.34 \mathrm{aA}$ & $28.35 \mathrm{aA}$ & $0.83 \mathrm{aA}$ & $4.60 \mathrm{aA}$ & $9.52 \mathrm{aA}$ & $9.27 \mathrm{aA}$ & 11.17 \\
\hline $\begin{array}{l}\text { Natural growth } \\
\text { shape }\end{array}$ & $10.67 \mathrm{aA}$ & $29.14 \mathrm{aA}$ & $0.85 \mathrm{aA}$ & $4.32 \mathrm{bB}$ & $8.94 \mathrm{cC}$ & $8.71 \mathrm{cB}$ & 10.25 \\
\hline
\end{tabular}

\section{Discussion and Conclusion}

There were many factors that affect the quality of citrus, including fertilization, irrigation, the use of soil wet growth regulators, and the position of the fruit on the tree. From this study, it can be seen that there were significant differences in fruit quality between different levels of Huangguogan canopy, and the difference in appearance quality was small and not significant; the differences in soluble solids, vitamin $\mathrm{C}$, and sugar content are more obvious. The overall performance was that the quality of the upper layer of the canopy was better than the lower layer, which was the same as the results of most people's research.

The level of soluble solids content had an important impact on the nutritional value, flavor and taste, and actual yield of the fruit. Wang Lihong [6] studied the correlation between different parts of the citrus crown and fruit quality and showed that the content of soluble solids was the highest in the middle and upper part of the crown, while the lower part and the periphery were lower than the inner part of the crown, which was extremely different from each other. In this experiment, the upper layer of the soluble solids canopy was higher than the lower layer.

Fruit quality largely depends on the type and amount of sugar contained in the fruit. The change of total sugar in different canopies of Huangguogan plant was characterized by higher content in the upper canopy, second in the middle, and lowest in the lower part. This was directly related to the position of the fruit and the planting density. If the canopy shades each other and the light was insufficient, the fruit sugar accumulation was low, poor quality. Peng Shunsi's [7] research on the fruit quality of ponkan fruit showed that the heterogeneity of nutrient absorption and distribution in different parts of the canopy leaf and root system may be the direct cause of the difference in fruit size and quality. Hong Yizhou [8] showed that the distribution of leaf temperature in the canopy of ponkans and the distribution of relative light intensity decrease from the top to the bottom of the canopy, and from the periphery of the canopy to the inner chamber. The distribution of temperature and wind has a significant effect. The distribution of relative light intensity and leaf temperature decreases from the upper part of the crown to the lower part, and from the periphery to the inside.
On the whole, the fruit quality in the Huangguogan plant was superior to the lower layer in the upper layer, and the round-headed fruit had the best quality. In fact, the quality of the happy-shaped fruit was related to the light, temperature and wind distribution in the canopy. Pruning and laying of reflective film can improve the light transmittance of the tree, adjust the light energy distribution and nutrient distribution of the tree, and help improve the quality of Huangguogan fruit. However, the reasons for these differences and the improvement methods need to be further studied.

\section{Acknowledgments}

This research was done independently by myself under the strict requirements and meticulous guidance of my tutor Zhihui Wang. My tutor's rigorous academic attitude and serious and sincere attitude have benefited me a lot. Finally, I would like to thank all the teachers and classmates who helped me in the process of writing the paper, as well as the cited or cited authors.

\section{References}

1. L.M.M., Liu, W.Q., Luo, H.Y., Wu, (2017) Study on the Whole Green Prevention and Control Model of Huangguogan in Shimian County,Farm Technology. 000(010):93.

2. D.H., Wang, J.T., Li. (1991) The selection and breeding of the fine line of HuangguoganGuiwankan, Chinese Citrus., 20(3):3.

3. S.J., Wertheim, P.S., Wagenmarkers. (2001) Orchard systems for apple and pear conditons for success. Acta Hort., 557:209-227.

4. C.L., Jiang, L.Z., Peng., L. Cao. (2006) The difference of soluble solid content between individual citrus fruits and different parts of the fruit. South China Fruit Tree., 35(2):3-5.

5. Shanghai Institute of Plant Physiology, (1999) A Guide to Modern Plant Physiology Experiments. Science Press, Shanghai.

6. L.H., Wang, H.L., Zhang, L.Q., Teng. (1997) Investigation on the Correlation between Different Parts of Citrus Crown and Fruit Quality. Zhejiang Citrus., 14(3). 
7. S.S., Peng, Z.Y., Peng. (1994) Study on the Quality of Citrus Fruit. Hunan Agricultural Sciences, Hunan.

8. S.B., Hong, X.H., Fan, X.P., Wang. (1989) The Microclimate Characteristics of Wenzhou Tangerine Canopy and Its Effect on Fruit Yield and Quality. Chinese Agricultural Meteorology., 10(2):16-19. 